\title{
EL PAPEL DE LAS CIUDADES EN LA CONSTRUCCIÓN DE LA NACIÓN ${ }^{1}$
}

\author{
Dra. Remedios Ferrero Micó ${ }^{2}$ \\ Universidad de Valencia (España) \\ Grupo de Investigación HISULA - SHELA \\ remedios.ferrero@uv.es
}

Recepción: 13/01/2009

Evaluación: 25/03/09

Aceptación: 20/04/2009

Artículo de Reflexión

\section{RESUMEN}

Una de las cuestiones importantes que surgieron en el periodo crucial 1810-1812 fue el de la legitimidad y la de la gobernabilidad. ¿Quién gobierna y en nombre de quién?, como ya planteó F.X. Guerra. Las ciudades reasumieron la soberanía y estuvieron al frente de las reivindicaciones nacionalistas. Ausente el monarca, se decide que la soberanía debe volver al pueblo de donde surgió. Ante la situación que vivía España el mundo americano se dividió de la misma manera que en la metrópoli. La disolución de la Junta Central y la constitución del controvertido Consejo de Regencia, conmovió a la sociedad americana y esa inquietud se reflejó en los cabildos. La ciudad como centro articulador y el pueblo, en torno a los cuales se organizan las actividades de los vecinos se constituyeron en un referente político. ¿Pero qué se entendió por pueblo? ¿Las ciudades con cabildo o las ciudades capitales que se atribuyeron ese derecho?

Palabras Clave: Cabildos, Legitimidad, Nación, Gobernabilidad, Soberanía, Monarquía, Nacionalismo, Independencia.

\footnotetext{
1 Este trabajo se inscribe en el Proyecto de investigación "Parlamentos y Ciudades en la Corona de Aragón. De la Historia a la Modernidad. II" (Ref. SEJ2006-10071/JURI, Plan Nacional de I + D 2006), Ministerio Educación y Ciencia. España

2 Doctora en Derecho, Catedrática de Historia del Derecho en la Universidad de Valencia. Investigadora principal de proyectos sobre Municipios y Parlamentos, investigadora del grupo Historia y Prospectiva de la Universidad Latinoamericana. "HISULA".
} 


\title{
THE ROLE OF THE CITIES IN THE NATION CONSTRUCTION
}

\author{
Dra. Remedios Ferrero Micó \\ Universidad de Valencia (España) \\ HISULA - SHELA Research Group \\ remedios.ferrero@uv.es
}

\begin{abstract}
One of the most important questions raised in the crucial period 1810-1812 was legitimacy and governability of the cities. Who governs and on behalf of who? as it was stated by F.X. Guerra. The cities retook the control of their sovereignty and fronted the nationalist demands. The king being absent, the cities decided that their sovereignty should return to the people from where it came from. In view of the situation of Spain, the American world was divided as in the metropolis. The break-up of the Junta Central and the constitution of the controversial Council of Regency touched the American society and that restlessness was reflected in the town councils. The cities, as central axis, and the towns, around which the activities of the neighbors are organized, constituted a political reference. But what was understood by towns? The cities with town council or the capital cities that attributed themselves that right?
\end{abstract}

Key Words: Town Councils, Legitimacy, Nation Gobernabilidad, Soberanía, Monarquía, Nacionalismo, Independencia.

\section{INTRODUCCIÓN}

La guerra de la Independencia propició un largo proceso de profundas transformaciones políticas, económicas, sociales y culturales que sacudieron Europa entre el último tercio del siglo XVIII y el primero del siglo XIX. Fue la era de las revoluciones liberales y de la pugna entre dos grandes potencias, la británica y la francesa. Es la época en que emergen nuevas naciones, unas con mucho empuje, como los Estados Unidos de América en 1776, y otras con divisiones sociales en su seno y difíciles relaciones entre ellas, como fue el caso de las nuevas naciones latinoamericanas.

Esta guerra supuso para América un hecho singular que contagió de vitalidad a las fuerzas políticas de la ciudad y el campo, de hecho llevaría a la escisión de las provincias 
de ultramar y la conformación en ellas de estados nacionales. La ideología surgida a comienzos del siglo XIX ayudó a acelerar la lucha por una nueva economía y una nueva sociedad. Las élites criollas participaron cada vez con mayor intensidad en las instituciones administrativas del régimen colonial controlando buena parte de la actividad financiera y comercial desde los cabildos, aunque tampoco conviene olvidar a la otra clase dominante procedente de la economía agraria tradicional. En todo caso la ciudad jugó un papel relevante en el momento revolucionario.

Con anterioridad a 1810, las quejas de los campesinos y de las clases menos favorecidas no habían sido escuchadas aunque desde diferentes esferas se simpatizara con las víctimas de las injusticias. En Nueva España la disensión política no abarcó las quejas de los campesinos. Tanto los autonomistas de 1808 como los conspiradores de 1809-1810 tenían objetivos más políticos que sociales. ${ }^{3}$

\section{Revolución y Léxico}

Los pronunciamientos surgidos por doquier acuñaron textos cuyo mensaje político era restituir a la nación las justas y sabias leyes promulgadas con anterioridad. En el marco de la guerra independentista se produjo una revolución también del léxico, de tal manera, que en ocasiones, se le está dando al término nación una acepción liberal, que puede hacer referencia a una idea progresista pero no popular. También habría que añadir el nuevo significado para la palabra pueblo que entró con fuerza entre 1810 y 1812 y que había surgido en la Revolución Francesa de 1789. En los primeros documentos de las Juntas, el pueblo, como referente territorial local pasa a ser el pueblo identificado con la nación, el Estado y la patria. Visto así, es fácil identificar nación y Estado y por tanto nación y soberanía, que en el caso de la península, las antiguas naciones que conformaron la Monarquía hispánica hasta 1808, pasaron a considerarse soberanas.

Una interpretación política de los sublevados trata de identificar Nación con el concepto de Patria. Según esta orientación, Patria representaría a sectores interesados en hacer triunfar la insurrección que culminara en el surgimiento de los Estados Nacionales Americanos. Pero ¿cómo crear una idea de nación si no hay acuerdo político sobre soberanía, religión o lengua?

En la inauguración de las sesiones de las Cortes de Cádiz, Muñoz Torrero y Manuel Luján, diputados por Extremadura, plantearon la cuestión de la soberanía popular. Defendieron la idea de que los diputados que componían el Congreso representaban a la Nación y en las Cortes residía la soberanía nacional. La Nación será la que reconozca a Fernando VII como Rey por lo que este planteamiento afectaría a la legitimidad del Estado. Esto nos lleva a otra de las cuestiones importantes que surgieron en el periodo crucial 1810-1812 como fue la legitimidad y la gobernabilidad.

3 HAMNETT, Brian R. (1990): Raices de la Insurgencia en México. Historia regional 1750-1824. México. Fondo de Cultura Económica. 


\section{Legitimidad y gobernabilidad}

¿Quién gobierna y en nombre de quién?, como ya planteó F.X. Guerra. ${ }^{4}$ Las ciudades reasumieron la soberanía y estuvieron al frente de las reivindicaciones nacionalistas. Ausente el monarca, se decide que la soberanía debe volver al pueblo de donde surgió. La Constitución de 1812 había supuesto el abandono de las ideas políticas del Antiguo Régimen y trazó las líneas a seguir hacia la organización del estado moderno tal como se conoce hoy. Las ideas de soberanía popular, entendiendo por tal que el poder reside en el pueblo, se convirtió en un modelo a seguir por otras constituciones, especialmente en América. La quiebra del Antiguo Régimen y de sus instrumentos de legitimación de la autoridad condujo a cambios sociales revolucionarios. El ideario ilustrado y liberal tuvo una influencia decisiva en conceptos como ciudadanía, Estado o constitución y definirán quienes son los sujetos del nuevo espacio público. En las Cortes de Cádiz se incidió en cuestiones de soberanía y representación que incluía a los territorios y súbditos de toda la Monarquía tanto americanos como peninsulares.

El diputado suplente por Santa Fe de Bogotá, José Mejía Lequerica, propuso a la Cortes que el tratamiento protocolario que debía darse a las Cortes fuera el de Majestad, una manera astuta de arrebatar jurídicamente el tratamiento del monarca y trasladarlo a los representantes de la Nación elegidos por votación popular. ${ }^{5}$ Era evidente que se trataba de un nuevo poder independiente pero falto de legitimación. Los americanos representados en las Cortes declararon que la Soberanía descansaba en la Nación, pero ¿una Nación conjunta de los españoles de ambos hemisferios o de varias Naciones según los territorios?

La actitud de pensar que es a partir de 1810 cuando surge la nación se comprende en el hecho de ser el comienzo de la lucha por independizarse de España, creyendo que eso significaba un rompimiento con el pasado y un nuevo nacimiento. En este supuesto se minimiza parte del pasado y se incurre en el error de no considerar la historia y las personas anteriores a esa fecha. La literatura romántica, foralista y decimonónica apunta en este sentido.

Vicente Boix, a mediados del siglo XIX, se planteaba cuestiones como la centralización y el concepto de Nación justificándolas en el pasado:

"La centralización ha cogido todos los hilos de la administración pública; ha concentrado en unas pocas manos todos los intereses, todas las ambiciones, todas las esperanzas y todos los vicios. El egoísmo sigue presidiendo este sistema; época de cábala y de agiotaje. Es horrible el despotismo que en el día se oculta bajo la máscara de lo que llaman Estado, á quien nadie conoce, y que hace sentir su tiranía, sin que

4 GUERRA, Françoise-Xavier. (1992): Modernidad e Independencia. Ensayos sobre revoluciones hispánicas. Madrid. Fundación MAPFRE.

5 CHUST, Manuel. (2000): "Revolución y autonomismo hispano: José Mejía Lequerica", en Revoluciones y revolucionarios en el mundo hispano, Ed. Manuel Chust. Castellón. 
podáis herirle en un costado. Comprendo el Estado bajo Felipe II y Carlos III; pero no lo hallo sobre el bufete de una turba de privilegiados. ¿Dónde está la Nación? Si la Nación es el Estado, ¿cuándo, en donde, cómo se encuentra representada?

Leyes, costumbres, tradiciones, dignidad, independencia; todo ha desaparecido en el fondo de esa laguna, llamada centralización; en ella se ha confundido todo; y se va devorando silenciosamente la vida nacional.

Sirve de consuelo, sin embargo, que el pueblo no ha renegado aun de su instinto patrio, llamado ahora con desde provincialismo; mejor para él: así al menos tiene un porvenir...

Se han acumulado sobre nosotros sistemas sobre sistemas. ¿Se ha fijado por eso el destino de nuestra España? Que respondan los partidos militantes. Los viejos dicen que es preciso volver á abrir el libro de nuestras leyes monárquicas. ¿Por qué arrojo yo, pues, esta crónica olvidada de mi patria en medio de la actividad del mundo actual? Para que se vea, para que se estudie, para que se aprecie, si vale; y en este caso se conceda una memoria á la época gloriosa de otra libertad. Yo bien sé que la sociedad actual apenas se digna creer ni esperar; sé que se levantan las contradicciones á cada paso, y que esa misma sociedad nos comunica su prematura vejez. Los que han pasado tienen razón en quererse detener, porque han visto cosas grandes, y su curiosidad se halla satisfecha. Pero nosotros iqué hemos visto? Tres Constituciones destrozadas. No importa: tres ensayos de la verdad en la vida humana, no bastan para conocerla. Tomad de mi libro lo que fuere bueno: si nada vale, olvidadle, y estimad mi sana intención"6.

Pero la Nación, en su sentido moderno, ¿es una construcción ideológica producto de una narrativa identitaria inventada? ¿Es el nacionalismo el que antecede a la Nación o viceversa?7 Son preguntas que merecen una consideración. No hay que olvidar el trasfondo de doctrinas que se enseñaron en las universidades, principalmente en la de Córdoba (Argentina). La teoría suareciana del poder derivado de Dios al pueblo, y de este al gobernante, y de la reasunción de ese poder por el pueblo en caso de tiranía o acefalia permitió sostener que disuelta la Junta de Sevilla, si el virrey había sido designado por ella cesaba en su función y el poder volvía a su sujeto primario que era el pueblo.

La otra teoría consideraba a los reinos o provincias de Indias vinculados mediante pacto a la Corona de Castilla, de forma que cuando en 1809 la Junta Central de Sevilla proclama que los dominios de España en Indias eran parte integrante de la Monarquía española, y lo reitera en febrero de 1810 el Consejo de Regencia, se considera que el cambio institucional unilateralmente decidido ha roto de modo ilegítimo el pacto de incorporación de los reinos indianos a la Corona castellana.

\footnotetext{
6 Hay que tener en cuenta la fecha en que está escrita a fines del año 1853. Se trata de una obra de exaltación romántica en la cual defiende la legislación foral anterior y la presenta como modelo de las nuevas constituciones. BOIX. (1855): Vicente Apuntes históricos sobre los fueros del antiguo reino de Valencia. Valencia. VIII a XI.

7 HOBSBAWN, E. J. (1990): Naciones y nacionalismo desde 1870. Barcelona.
} 


\section{El papel de los cabildos}

Ante la situación que vivía España, ausente el monarca, el mundo americano se dividió de la misma manera que en la metrópoli. La disolución de la Junta Central y la constitución del controvertido Consejo de Regencia, conmovió a la sociedad americana y esa inquietud se reflejó en los cabildos. La ciudad como centro articulador, en torno a la cual se organizan las actividades de los vecinos constituyó un referente político y optó por una denominación: pueblo ¿Pero qué se entiende por pueblo? ¿Las ciudades con cabildo o las ciudades capitales que se atribuyen ese derecho?

La retroversión del poder a la comunidad se justificaba por el cautiverio del monarca, si el Rey está ausente, la soberanía vuelve a los pueblos en donde se origina. En el Virreinato de la Plata desaparecida la institución que había investido de autoridad al virrey Cisneros el decreto de 17 de octubre de 1810, renovó el cabildo de Buenos Aires y obligó a los capitulares a "jurar al Pueblo ante la Junta, que sostendrán con dignidad su representación". Otra cuestión fue la reasunción del poder por la comunidad, pero no operada en un solo pueblo o parte de ella, sino en todos sus pueblos en común. La decisión de Buenos Aires, provisional, exigía del posterior concurso de los demás pueblos del virreinato para participar en la capacidad política retrovertida a la comunidad. Cuando llega a Buenos Aires la noticia de que ha caído la Junta de Sevilla, se realiza un Cabildo abierto el 22 de mayo de 1810 con el fin de decidir si una vez desaparecido el órgano gubernativo que nombró al virrey el gobierno debía pasar al Cabildo de Buenos Aires. ${ }^{9}$

Asimismo, el 18 de septiembre de 1810 se reunió el cabildo presidido por el gobernador del reino de Chile, conde Mateo de Toro y Zambrano siendo nombrado presidente de la primera Junta de gobierno que marcaría el camino para la independencia de Chile. Contó con la asistencia de "los jefes de todas las corporaciones, prelados de las comunidades religiosas y vecindario noble de la capital". ${ }^{10}$ Pero el cabildo abierto ${ }^{11}$ convocado en Montevideo el 21 de septiembre de 1808 y la instalación de la Junta de Montevideo fue un episodio sin antecedentes dentro de la organización colonial que marcaría el comienzo de una etapa para el continente americano de formación de una conciencia autonómica. Los ciudadanos de Montevideo se erigieron en dueños de sus destinos en abierta rebeldía contra la autoridad virreinal, rompiendo los lazos que le unían a Buenos Aires para asumir la representación de su propio gobierno mediante la instalación de una Junta cuyo reconocimiento exigió "a ejemplo de las que se han

\footnotetext{
8 SAENZ VALIENTE, José María. (1952): Bajo la campana del cabildo. Organización y funcionamiento del cabildo de Buenos Aires después de la Revolución de mayo (18101821).Buenos Aires.

9 BIDART CAMPOS, Germán J. (1992): "El proceso político-constitucional de la república Argentina desde 1810 a la actualidad", en AYER.

10 ARANGUIZ DONOSO, Horacio. (1972): "Estudio institucional de los cabildos abiertos de Santiago de Chile (1541-1810), III Congreso del Instituto Internacional de Historia del Derecho Indiano. Actas y Estudios, Instituto Nacional de Estudios Jurídicos. Madrid.

${ }_{11}$ En la Recopilación de Leyes de los Reynos de las Indias de 1680 hay dos leyes que hacen referencia a los cabildos abiertos, libro 4, título 10, ley 3 y libro 4, título 11, ley 2 .
} 
mandado crear por la Suprema de Sevilla en todos los pueblos del Reino que contengan el número de dos mil vecinos".

La importancia de este hecho radica en la decisión tomada en un cabildo abierto frente a una representación del poder colonial que alcanzaría una proyección histórica por ser el inicio del desmoronamiento de la autoridad colonial. ${ }^{12}$ Los acontecimientos posteriores desembocaron en la reacción del pueblo de Montevideo que "conmovido" impuso finalmente su voluntad a pesar de la causa promovida por la Audiencia de Buenos Aires. El gobernador de Montevideo y los vocales de la nueva Junta en escrito de 7 de octubre de 1808 ante la provisión enviada por el Regio Tribunal ordenándoles que disolviera la Junta alegaron: "Cualesquiera que sea el juicio de ese Regio Tribunal en orden a los referidos documentos le parece al Gobernador y a los vocales que debe declararse que la Junta erigida por unánime consentimiento del pueblo fue legítima y acaso inspirada por el Cielo". ${ }^{13}$

Las ciudades fueron las que reasumieron la soberanía y lideraron la lucha por la independencia. José Artigas, que lideró la revolución de la Banda Oriental defendería la "soberanía particular de los pueblos". Artigas, que pertenecía al Cuerpo de Blandengues desertó en 1811 y se dirigió a Buenos Aires para ponerse al servicio de la recién creada Junta Grande. Desde allí regresó a la Banda Oriental y emprende la revolución desde la campaña hacia Montevideo.

El movimiento revolucionario en el Río de la Plata y en la Banda Oriental adoptó unas características peculiares. Este territorio fronterizo fue fuente de continuas disputas entre España y Portugal. Montevideo, no tenía jurisdicción sobre toda la Banda sino sólo sobre un pequeño territorio circundante y el resto estaba sometido a la jurisdicción de Buenos Aires. Ambas ciudades rivalizaban por su actividad portuaria y disputaban por la primacía de la región. "Frente a la creación de la Junta de Mayo, Montevideo defendía la opción regentista en 1810 proclamando su lealtad al Consejo de Regencia". ${ }^{14}$

El 21 de septiembre de 1808 los vecinos y autoridades de Montevideo, reunidos en cabildo abierto, desconociendo la autoridad del virrey, reasumieron

\footnotetext{
12 Los cabildos ya venían rebelándose contra cualquier intromisión que a la larga resultó irremediable. Existía una confrontación constante entre los integrantes natos del cabildo, de origen popular y la monarquía siempre proclive a intervenir. Los cabildos lo que pretendían era la representación popular que, en cierta medida el rey permitió aceptando que las elecciones de cargos se realizaran según las costumbres de cada lugar. Pero comenzará su declive en el siglo XVII y gran parte del XVIII acentuado por el gobierno borbónico debido a su mayor intervencionismo. La estructura institucional de los municipios, tanto de indígenas como de españoles, se vio afectada por la reforma de Carlos III. La centralización que impuso afectaría a los cabildos que verían mermada su relativa autonomía con la creación de las intendencias. 13 "Sobre la disolución de la Junta llamada de Gobierno creada en la ciudad de Montevideo, y recurso de Súplica interpuesto por ella, Buenos Aires," octubre 7 de 1808. Documentos relativos a la Junta Montevideana de Gobierno de 1808, Junta Departamental de Montevideo. Montevideo. 1958, p. 51.

14 PIVEL DEVOTO, Juan E. (1957): Raíces coloniales de la revolución oriental de 1811. Montevideo.
}

Rhela. Vol. 12. Año 2009, pp. $111-128$ 
sus derechos soberanos formando una junta de gobierno surgida por su voluntad siendo el precedente del que surgió la emancipación del continente americano. A partir de 1810 los cabildos abiertos proclamaron abiertamente la separación de España. ${ }^{15}$

El camino a la secesión estaba abierto. El 10 de agosto de 1809 se había redactado la constitución de la nueva Junta Suprema de Quito, con carácter fidelista; En Quito el primer grito de libertad se dio el 10 de agosto de 1809. En el municipio se reunieron los Diputados del pueblo y ratificaron con su firma la independencia recién proclamada. El 19 de agosto de 1809 la provincia de Quito declara su independencia de la Corona española. El 19 de abril de 1810 el cabildo de Caracas constituye un gobierno autónomo y los criollos instituyen la Junta Suprema de Caracas de carácter autonomista. El 22 de mayo de 1810 se reúne en Cartagena un cabildo extraordinario que establece la Junta Suprema de Gobierno; el 25 de mayo de 1810 se estableció la Junta de mayo en Buenos Aires; el 20 de junio de 1810, se proclama la Junta Suprema de Santafé, también autonomista; el 3 de julio de 1810 se firma en Cali un acta en contra de la dominación española; el 6 de agosto de 1810 Monpox crea una Junta Autónoma de Gobierno. El 5 de junio de 1811 las provincias unidas de Venezuela declaran la independencia de España; el 4 de diciembre de 1811 en el primer Congreso de los Pueblos Libres de la "Presidencia de Quito se adopta el acuerdo de independencia; la provincia de Tunja proclamó la primera constitución republicana de la Nueva Granada, el 9 de diciembre de 1811, en la cual se niega la soberanía del rey y, el 15 de febrero de 1812 sale a la luz la que consagra la nueva forma de gobierno en Nueva Granada". ${ }^{16}$ "En Buenos Aires, la semana de mayo había llevado al fin del gobierno virreinal y de la dominación española al consumarse la independencia del virreinato respecto de la Corona de España". ${ }^{17}$

\footnotetext{
15 La suerte de los municipios indianos durante la independencia fue motivo de reflexión por uno de los entusiastas de la institución municipal: Domingo Faustino Sarmiento. Sus ideas evolucionaron desde el pesimismo, con opiniones desfavorables en Comentarios de la Constitución de la Confederación Argentina en la que elogiaba el régimen municipal español del siglo XVI pero que dice fracasó en América debido a factores sociales, hasta 1883, treinta años más tarde, que se declara admirador de los primeros cabildos considerando que estaban mejor en la época indiana que en la suya propia. Para justificarlo recuerda el acto de la fundación de la ciudad de Córdoba (Argentina) en cuya acta de fundación consta que el gobernador don Gerónimo Luis de Cabrera, en nombre del monarca español le dio a la ciudad todas las franquicias, mercedes y libertades que tiene la ciudad de Córdoba en España. Llega incluso a establecer un paralelismo entre las instituciones inglesas e indianas al resaltar las instrucciones dadas en 27 de febrero de 1592 por el cabildo de Córdoba a los apoderados que debían representarlo ante el capitán general de Tucumán en defensa de sus prerrogativas. Quizá lo que más destaca es la intervención en el gobierno de los vecinos. Carlos Mouchet, "Sarmiento y sus ideas sobre el municipio indiano", V Congreso Histórico Municipal Interamericano, Ciudad Trujillo 1952, T.I, pp.191-200.

16 PÉREZ O, Eduardo. (2005): La Guerra irregular en la Independencia de la Nueva Granada y Venezuela, 1810-1830, Universidad Pedagógica y Tecnológica de Colombia. En dicha obra cita a OCAMPO LÓPEZ, Javier "El Proceso Político, Militar y Social de la Independencia", en Manual de Historia de Colombia, T.II, pp. 26 - 45. Oscar Efrén Reyes, Breve Historia General del Ecuador, T. I, pp.307-348, HUERTAS RAMÍREZ, Pedro Gustavo, "La Constitución de la República de Tunja y su proyección histórica" en Boyacá, perfiles históricos de identidad regional y nacional, pp. 179-188.

17 La conocida como "Revolución de Mayo" se inició el 25 de mayo de 1810, fecha importante para los independentistas de la América Latina y por tanto para el Virreinato del Río de la
} 
El último virrey con sede en Buenos Aires, Baltasar Hidalgo Cisneros, había llegado al Rio de la Plata en julio de 1809, designado por la Junta Central de Sevilla, cuando a mediados de mayo llega a Buenos Aires la noticia de que ha caído la Junta de Sevilla, se prepara y realiza el cabildo abierto el día 22 a fin de decidir si al desaparecer el órgano gubernativo español que había nombrado al virrey, cesaba la autoridad de éste en el virreinato, y en caso afirmativo, si debía abdicar en el cabildo de Buenos Aires. Reunido el cabildo abierto se resuelve la cesación del virrey Cisneros y a la vez, que la autoridad debía recaer provisionalmente en el cabildo. Según Zorraquín, en el cabildo abierto del 22 de mayo se explicó originariamente la doctrina que sirvió de base jurídica a la revolución. ${ }^{18}$ "El movimiento de Mayo se apoyó, dice, en dos ideas fundamentales: la caducidad del gobierno legítimo de España y por tal razón el ejercicio del poder volvía al pueblo de Buenos Aires"19.

El cabildo formó una Junta presidida por el virrey e integrada por otro cuatro miembros, pero dicha Junta, pese a ser jurada el 24 de mayo, es resistida y renuncia. Una nueva Junta se forma el 25 de mayo y ya no la integra el virrey y según proclamó el 26 de mayo debía "sostener estas posesiones en la más constante fidelidad y adhesión a Fernando VII y sus legítimos sucesores en la Corona española". El cabildo abierto del día 25 dio paso, por amplia mayoría, a los que delegaron en el ayuntamiento la designación de la Junta, siguiendo a Saavedra. "La teoría jurídica que sustentó el movimiento de Mayo, según Zorraquín, se basó " 1 " en la afirmación no discutida por sus adversarios-de que había caducado el gobierno legítimo de todo el imperio; $2^{\circ}$ en que producida esa situación, el pueblo de Buenos Aires recuperaba su autoridad originaria o los derechos de la soberanía; y $3^{\circ}$ en que esa reversión le permitía instalar un nuevo gobierno, sin perjuicio de la consulta ulterior a las demás ciudades del virreinato". ${ }^{20} \mathrm{El}$ uso del término "soberanía", indica la influencia de autores más modernos pertenecientes a la escuela del derecho natural racionalista. ${ }^{21}$ Parece claro el trasfondo de doctrinas que por su enseñanza en las universidades, principalmente Córdoba, se observa.

La retroversión del poder a la comunidad encontraba base en el cautiverio del rey al que se sumaba la desaparición de la Junta de Sevilla que había investido de autoridad al virrey Cisneros y el no consentimiento de los virreinatos los desligaba de la obediencia debida al rey. La decisión de Buenos Aires exigía del posterior concurso de los demás pueblos del virreinato para participar en la capacidad política retrovertida a la comunidad.

\footnotetext{
Plata. Germám J. Bidart Campos, "El proceso político-constitucional de la república Argentina desde 1810 a la actualidad", Ayer 8, 1992, 163 y ss.

18 ZORRAQUÍN BECÚ, Ricardo. (1960): "La doctrina jurídica de la revolución de mayo", en Revista del Instituto de Historia del Derecho, $\mathrm{N}^{\circ} 11$, 47. Buenos Aires. 1960, p.47

19 Ibídem, p. 52

${ }^{20}$ Ibídem, p.58

${ }^{21}$ En un artículo posterior titulado "Algo más sobre la doctrina jurídica de la revolución de mayo", publicado también en la Revista del Instituto de Historia del Derecho, p. 139, Ricardo Zorraquín Becú sostiene y se ratifica en la influencia de origen racionalista del pensamiento de Mayo, en contra de lo que opinaba Roberto H. Marfany que defendía la doctrina jurídica de filiación escolástica.
}

Rhela. Vol. 12. Año 2009, pp. $111-128$ 
En aplicación de esta teoría, la Junta de mayo envión una circular a las autoridades del interior encareciéndoles el nombramiento de diputados, uno por cada ciudad o villa, para que se incorporaran a dicha Junta. Se formó así la Junta Grande el 18 de diciembre de 1810. La instalación de este primer gobierno criollo en el Rio de la Plata significó el cese efectivo de la autoridad española en el virreinato aunque ese primer gobierno criollo se tiene por constituido en nombre del rey Fernando VII. La invocación a Fernando VII, fue muy distinta de la que antes había presidido Javier Elío en septiembre de 1808 en Montevideo. La diferencia radicó en que la Junta Patria, nacida por presión revolucionaria, fue integrada, casi totalmente, por criollos que provenían de sectores corporativos o profesionales y que estaban políticamente comprometidos con distintos grupos abocados al cambio.

La colaboración del cabildo con la Junta Grande avanzó hacia una creciente intervención del cabildo, contribuyó su peso político y la representación del pueblo atribuida al cabildo como receptor de las demandas sociales. Así se aprecia a raíz de lo sucedido el 5 de abril de 1811, en que varios individuos entraron a la sala de Juntas y "expusieron a voces que el pueblo se hallaba congregado en la Plaza de la Victoria para representar al Gobierno lo conveniente a sus derechos, y que lo haría precisamente al amanecer del día siguiente por intermedio del excmo. Cabildo." ${ }^{22}$ En esta coyuntura se convocó a cabildo abierto y de el surgieron los nombres de los fututos triunviratos.

El camino hacia la emancipación del Rio de la Plata se fue gestando y tomando fuerza por la conciencia de los criollos como sector diferenciado de los españoles peninsulares. Virrey y Audiencia representaban a la Corona y el Cabildo a los criollos. Los sucesos de mayo no fueron improvisados, la oposición de los comerciantes peninsulares que dominaban el cabildo había emergido con fuerza en Buenos Aires y desde allí se acusó al virrey Liniers de ser sospechoso de favorecer los intereses de los españoles americanos. Al virrey también se oponía el gobernador de Montevideo Elío que propició su derrocamiento. La llegada a Buenos Aires en 1808 del comisionado francés Marqués de Sassenay derivó en el episodio de la rebelión de Alzaga de $1^{\circ}$ de enero de 1809. Aunque Liniers se negó a obedecer órdenes para el reconocimiento de José Bonaparte como rey de España e Indias y explicó su posición en proclamas de 15 y 27 de agosto de $1808,{ }^{23}$ la duda se cernió sobre él y llevó a su destitución.

\footnotetext{
22 SAENZ VALIENTE, José María. (1952): Bajo la campana del cabildo. Organización y funcionamiento del cabildo de Buenos Aires después de la revolución de Mayo (1810-1821), Buenos Aires. Señala Sáenz que la representación del pueblo tenía su símbolo en la campana capitular, que fue retirada a raíz de de los sucesos del $1^{\circ}$ de enero de 1809 , recuperándola el cabildo en noviembre de 1810 .

23. ARCHIVO GENERAL DE INDIAS, Audiencia Buenos Aires, leg. 94. En la proclama del día 15 Liniers resalta que "yo no me he detenido en contestar que fidelidad de este pueblo a su legítimo Soberano es el carácter que más le distingue, y que admitiré con aprecio toda clase de auxilios, que consistan en armas, municiones y tropas españolas". Elio contestó a Liniers y le matizó:"No se equivoca V.E. en creer que los fieles habitantes que tengo el honor de mandar, se sacrificarán conmigo para conservar estas Provincias; pero no para otro Soberano que no sea Fernando VII. V.E. creía que para tomar su partido, debía esperar el éxito de los sucesos de España: Yo soy de muy distinto parecer: jamás dude de que los generosos y fieles españoles temerían: soy español, los conozco mucho, he hecho con ellos la guerra contra la
} 
"Lealtad, honor y patriotismo", son las tres columnas en que Liniers basó el edificio americano. Pero Liniers tuvo que hacer frente a muchas acusaciones. En un largo informe, fechado el 16 de marzo de 1809, dirigido a S M. le informó sobre su postura respecto a "las ideas peligrosas y opuestas a la constitución del Estado", que establecieron en un papel dos españoles americanos, en donde "sea por ignorancia, ó por ideas interesadas, establecen principios tan perniciosos a la salud del estado, como opuestos a las sabias leyes de Indias que han mantenido más de trescientos años estos remotos establecimientos en estrecha unión y armonía con su Metropli." ${ }^{24}$ Achaca los errores cometidos por los dos españoles americanos a su interés por imitar "las sofisterías del caviloso Necker." 25 Su opinión sobre Francia no deja lugar a dudas "La Francia ofrece a todas las Naciones una lección terrible de las desgracias que trae consigo el espíritu de novedad”, quizá para despejar las sospechas de bonapartismo que ensombrecieron el final de su virreinato y que Elio le reprochaba constantemente.

En su escrito le sugiere al monarca que si tiene que premiar a alguien que sea a los que se han distinguido en la defensa de los dominios americanos y no a los cabildos porque aumentarían su poder. Se opone al nombramiento de diputados para la corte porque serviría para desorganizar el sistema político y abriría el camino de la independencia. Como se ve, se trata de dos concepciones diferentes e irreconciliables de cómo debía gobernarse en América

En el mismo informe que manda al rey, después de rebatir las alegaciones efectuadas por los dos españoles americanos, propone al monarca algunos medios conducentes a la organización de los dominios americanos ${ }^{26}$, valiéndose de los conocimientos adquiridos en veinte años de residencia en ellos:

1. Los virreyes deben ser capitanes generales mandando ejércitos con poder ilimitado para la organización de las tropas, debiendo sólo en los grandes proyectos

\footnotetext{
Francia. Pero si por desgracia la España, ó alguna parte de ella fuese de distinto parecer, á la misma España declararía la guerra...y a todo individuo que no preste guerra y guerra hasta la muerte", Reimpresión de la Casa de Misericordia de Cádiz.

24 ARCHIVO GENERAL DE INDIAS, Audiencia Buenos Aires. "El Virrey de Buenos Ayres. Manifiesta las ideas peligrosas y opuestas a la constitución del Estado, que establecen en un papel que presentaron a V. M. dos Españoles Americanos". Se trata de un informe de 100 folios, firmado por el propio Liniers y en el que además de defenderse de las acusaciones vertidas sobre él, explica cual es su idea sobre el gobierno americano, especialmente el papel que debe desempeñar el virrey, cabildos y consulados. Este documento, anterior a la carta de 19 de mayo de 1810 dirigida al virrey Baltasar Hidalgo de Cisneros, considerada como la última revelación política de Liniers según Enrique de Gandía, es de enorme trascendencia para conocer el pensamiento político de Liniers sobre los acontecimientos y el gobierno político del Río de la Plata

25 Aunque no menciona cual de las obras pudo ser la perniciosa es posible que se refiera a alguna de estas, Jerónimo Necker, Del poder ejecutivo en los grandes Estados, París, 1782. Administración de la Real Hacienda en Francia, París, 1784. Importancia de las opiniones religiosas, Londres, 1788.

26 ARCHIVO GENERAL DE INDIAS, Audiencia Buenos Aires, leg. 96. "El Virrey de Buenos Ayres. Manifiesta las ideas peligrosas y opuestas a la constitución del Estado, que establecen en un papel que presentaron a V. M. dos Españoles Americanos", apartados 21 y siguientes del informe.
} 
consultar al monarca para su aprobación. "Es bien irregular que un Capitán general esté sujeto al voto de la Junta Superior de Real Hacienda", escribe.

2. Un Capitán general responde de la defensa de la tierra y debe arbitrar lo que considere útil para ese fin, siendo el Ministerio de la Guerra y el Supremo Consejo los que juzguen si se excede en ello. El Superintendente de la Real Hacienda "no sirve más que para aumentar sus dictados con dispendio del tiempo en echar firmas sobre providencias de su asesor".

3. El Virrey debe utilizar para el castigo de los delitos de robo, homicidio, vagos y mal entretenidos autoridad Prebostal, como en Nueva España, porque son delitos de fácil comprobación y están sujetos a Leyes marciales, y de este modo se libera a las Audiencias de trabajo

4. El Superintendente no debe tener más jurisdicción que la de la Real Hacienda, el arreglo de oficinas y poner las partes administrativas en orden, así se evitan las quiebras escandalosas que han devorado el erario.

5. Los cabildos deben componerse de seis regidores, hombres hacendados y de conocida probidad, cada uno, a lo menos, con mil pesos de sueldo. Se les daría el tratamiento de señoría y de esta manera servirían gustosos estos empleos. ${ }^{27}$ El Virrey, de acuerdo con la Real Audiencia, los nombraría hasta la confirmación real, pudiendo ser suspendidos, con justa causa, por las autoridades que los elijan. Las elecciones quedarían reducidas a dos alcaldes y un Procurador, sirviendo los primeros dos años, siendo precisamente de primer voto el que el año anterior hubiese estado de segundo.

Históricamente, el cabildo había sido una institución de la administración municipal castellana trasplantada a Indias, aunque con retoques, debidos a la existencia de una realidad distinta en el Nuevo Mundo. La ciudad indiana demostró una capacidad extraordinaria para adaptarse a lugares y a circunstancias especiales.

Según la legislación, los cabildos en Indias son instituciones de carácter corporativo que ostentan el gobierno y la representación de la población, constituyendo su misión más importante el gobierno de la ciudad y de su término territorial. ${ }^{28}$ Gozaban de autonomía, al menos formalmente, como se desprende de algunas disposiciones de Carlos I, Felipe II y Felipe III. ${ }^{29}$ El emperador, desde Monzón, en 1528, donde se encontraba celebrando Cortes generales para los reinos de la Corona de Aragón, dispuso

\footnotetext{
27 A fines del siglo XVIII el sueldo de los cabildantes era escaso, interesando estos cargos sólo por el prestigio que conferían a los nuevos miembros de la oligarquía. El desinterés por el autogobierno se hará patente y sólo recobraría nuevos bríos a comienzos del XIX por el resurgimiento de una conciencia americana que soñaba con independizarse de la metrópoli. ${ }_{28}$ RECOPILACIÓN DE 1680, lib. 9, tit. 15. La palabra cabildo deriva de capítulo, y ésta a su vez de la latina caput, equivalente a la reunión del alcalde, regidores y demás individuos que componen el cuerpo municipal. También se designa así el lugar o sitio donde tiene lugar la reunión de los mismos. Cabildo de Indias, según la Enciclopedia Española, es en lo civil lo propio que ayuntamiento. El título 1, lib. 2 de la Recopilación de Indias, que habla de estas corporaciones, lleva por epígrafe de los cabildos y concejos, y es tan constante esta denominación, que apenas se hallará una sola vez en dicho código la voz ayuntamiento, aunque sí después.

${ }^{29}$ FERRERO MICÓ, Remedios. (2001): "El cabildo como fuente de autonomía municipal", en Revista del Archivo Histórico de la Municipalidad de Córdoba. № 2. Córdoba, pp.59-73.
} 
que las ciudades, villas y lugares de las Indias, no celebraran cabildos, ni eligieran oficiales sino fueran en las casas del cabildo, que para eso estaban dedicadas. Felipe II reitera la disposición anterior e insiste que "los gobernadores hagan los cabildos en las casas del ayuntamiento, y no en la suyas, no habiendo causa tan grave, ni relevante, que obligue a lo contrario, y no lleven ni consientan, que intervengan Ministros Militares, ni den a entender a los capitulares, por obra ni palabra, causa, ni razón, que los pueda mover, ni impedir la libertad de sus votos, guardando en esto, y en lo demás que se confiere, todo secreto y recato". Por su parte Felipe IV en 1642 recuerda a los gobernadores y sus tenientes que no perturben a los regidores y que les dejen votar en los cabildos con toda libertad, sin presión ni presencia de otras autoridades.

Pero con la venta de oficios se aprecia la subordinación política de las ciudades y villas que sólo se contrarrestaría en los albores del movimiento independentista. Los cabildos se van a rebelar contra cualquier intromisión que a la larga, resultará irremediable. La esencia popular se va mitigando por la aparición de los regidores perpetuos. Por eso es corriente que a la institución municipal se le denomine cabildo, justicia y regimiento dando a entender su origen. Cabildo en cuanto es popular y regimiento en cuanto es de origen real. La pujanza de los cabildos es mayor en el siglo XVI coincidiendo con la institución de los cabildos abiertos donde todos los habitantes podían concurrir, hablar y votar, aunque no pueden confundirse con las asambleas populares pues se reunieron pocas veces y solo para resolver asuntos de gran interés. Después comenzará su declive en el siglo XVII y gran parte del XVIII acentuado por el gobierno borbónico debido a su mayor intervencionismo. La estructura institucional de los municipios, tanto de indígenas como de españoles, se vio afectada por la reforma de Carlos III. La centralización que impuso afectaría a los cabildos que verían mermada su relativa autonomía con la creación de las intendencias. Pero por otra parte, la centralización de las decisiones municipales supuso una mayor eficacia en la administración de la vida local. ${ }^{30}$

No obstante, la autonomía del cabildo, las intromisiones a nivel municipal por parte de las autoridades superiores fueron constantes. Estas no se aceptan de buen grado y fueron combatidas persistentemente por parte del cabildo que presentaba recursos judiciales que llegaron hasta el Consejo de indias y al mismo rey. Pero a pesar de los argumentos jurídicos, la costumbre y razón alegadas ante virrey o Real Audiencia, la interferencia de los gobernantes superiores se intensificó en el tiempo. ${ }^{31}$

El cabildo de la ciudad de México conoció en sus primeros momentos de la intromisión de las autoridades superiores habiéndose intensificado durante el gobierno de la primera Audiencia al destituir ésta a los alcaldes ordinarios de la ciudad. Desafiando

\footnotetext{
30 BARAHONA, Marvin. (1996): La Alcaldía Mayor de Tegucigalpa bajo el régimen de Intendencias (1788-1812), Instituto Hondureño de Antropología e Historia, Tegucigalpa, Honduras.

31 El cabildo de México, durante el gobierno de la primera Audiencia vio como se destituyeron a los alcaldes ordinarios como primer acto de dominio. Guillermo Porras Muñoz, El gobierno de la ciudad de México en el siglo XVI, UNAM., México, 1982.
} 
a la Real Audiencia tres regidores se pronunciaron por la reelección de los alcaldes destituidos. La segunda Audiencia fue más respetuosa con las decisiones del cabildo pero la legislación real oscilaba, pues igual prohibía en 1530 a los miembros de la Audiencia asistir a las sesiones capitulares que seis años más tarde, otra real cédula, autorizaba a uno de los oidores de la Audiencia a entrar en el cabildo con voz y voto. El virrey Mendoza no asistía a las sesiones del cabildo pero se hacía informar de sus acuerdos modificándolos en el punto que le convenía. Uno de los virreyes que más interfirió fue el marqués de Villamanrique que llegó a intervenir en la elección de los alcaldes. El cabildo no se resistía a perder su autonomía y protestó ante el monarca que dictó una real cédula en 1588 no autorizando semejante práctica. ${ }^{32}$

Los Austrias lograron introducir unos regidores perpetuos de nombramiento real, ${ }^{33}$ pero a partir del siglo XVII el cargo de regidor se podrá vender o transferir y si no se hacía en vida revertía a la Corona. ${ }^{34}$ La venta de regidurías ofreció la oportunidad a los criollos de ocupar esas plazas y paulatinamente fueron desempeñados por las familias locales de mayor peso económico dando origen a un cabildo colonial de carácter oligárquico como sucedía en los municipios peninsulares. Pero la falta de compradores llevó, bien a reducir el número de regidores bien, a acudir a la designación directa. El cabildo de Cartagena al resultarle difícil encontrar postores para los remates de los distintos oficios concejiles, solicitó del virrey en 1819 que los redujese a los dos tercios de los señalados en la ley. ${ }^{35}$

Las dificultades para proveer los distintos oficios concejiles por falta de postores se atestiguan por las reiteradas comunicaciones dirigidas al Virrey. Es posible que se debiera a las incapacidades establecidas en la legislación para el desempeño de oficios por razones de parentesco con personas que ya estuvieran desempeñando esos cargos municipales o por tratarse de individuos que no supieran leer ni escribir. También porque debido a que el sueldo de los cabildantes eras escaso, estos cargos sólo interesaban por el prestigio que conferían a los nuevos miembros de la oligarquía.

El desinterés por el autogobierno se hizo patente, recobrando nuevos bríos a comienzos del XIX por el resurgimiento de una conciencia americana que soñaba con independizarse de la metrópoli. La modalidad de cabildo abierto, debido a su composición más amplia, jugará un papel importante en el inicio de la Independencia. La invasión napoleónica fue la causa que provocó se convocaran nuevamente una serie de cabildos abiertos en los dominios americanos.

\footnotetext{
${ }^{32}$ PORRAS MUÑOZ, Guillermo. (1982): El gobierno de la ciudad de México en el siglo $X V I$, UNAM, México.

${ }^{33}$ En Córdoba (Argentina) fueron seis con derecho a voto, Jorge Roberto Emiliani, El cabildo, Cuadernos de Historia, 13, Junta Provincial de Historia de Córdoba, 1992

${ }^{34}$ Que en las Indias se vendan los oficios, que por esta ley se ordena, Recopilación de Leyes de los Reynos de las Indias, 8, 20, 1

${ }_{35}$ OTS CAPDEQUí, José María. "El régimen municipal del Nuevo Reino de Granada al tiempo de la Independencia".
} 
Estas asambleas normalmente tenían carácter deliberativo y sus resoluciones no vinculaban. Se convocaban excepcionalmente para la discusión de asuntos graves y se consideró que ese era uno de ellos. En un primer momento tuvieron como finalidad recolectar dinero para ayudar a la guerra de Independencia de España, jurar lealtad a Fernando VII, reconocer la junta de regencia y por último elegir juntas locales de gobierno que prepararan la separación de España. Ya hemos visto como el 21 de septiembre de 1808 los vecinos y autoridades de Montevideo, reunidos en cabildo abierto, desconociendo la autoridad del virrey, reasumieron sus derechos soberanos formando una junta de gobierno surgida por su voluntad siendo el precedente del que surgió la emancipación del continente americano y como a partir de 1810, los cabildos abiertos, proclaman abiertamente la separación de España.

\section{CONCLUSIONES}

Luego de la invasión napoleónica, que provocó la caída de la monarquía, la disolución de la Junta Central y la constitución del controvertido Consejo de Regencia, la sociedad americana había quedado conmovida y esta inquietud se reflejó en el cabildo.

Hacia 1808 la monarquía se encontraba con un grave deterioro de autoridad. Las abdicaciones de Bayona, supusieron despojarse de la soberanía y concluyeron con el éxito de las tropas francesas sobre el territorio peninsular. Ante esta situación se produjo el levantamiento nacional y la reasunción de la soberanía por el pueblo. Esta crisis, desencadenada en la metrópoli, llegó con sus efectos a América donde confluyó con factores de profundo descontento social que culminarán con los movimientos de emancipación. ${ }^{36}$ El éxito estuvo condicionado tanto por factores internos, no hay que olvidar el hundimiento de la Hacienda Real, como externos, con base en los intereses de otras potencias, principalmente Inglaterra, que buscaba el control de los mercados de las colonias españolas.

1810 fue el año clave para los movimientos independentistas de América latina. La modalidad de cabildo abierto, debido a su composición más amplia, jugará un papel importante en el inicio de la Independencia. La invasión napoleónica trajo como consecuencia se convocaran nuevamente cabildos abiertos en los dominios americanos de los cuales surgiría la emancipación del continente.

${ }^{36}$ MARTIRÉ, Eduardo. (2001): 1808 Ensayo histórico-jurídico sobre la clave de la emancipación hispanoamericana, Buenos Aires. 


\section{FUENTES}

ACTAS DEL CABILDO DE SAN JUAN BAUTISTA DE PUERTO RICO, 18031809, (1970), transcripción y notas R. Caro de Delgado, Publicación oficial del Municipio de San Juan, Puerto Rico.

ARCHIVO GENERAL DE INDIAS, (1810). Audiencia Buenos Aires, legs. 94, 96.

CARTAS DE CABILDOS HISPANOAMERICANOS. AUDIENCIA DE MÉXICO. (SIGLOS XVI Y XVII) Y (SIGLOS XVIII Y XIX), (1985-1999), 2 vol. Sevilla

RECOPILACIÓN DE LEYES DE LOS REYNOS DE LAS INDIAS, (1680).

\section{SELECCIÓN BIBLIOGRÁFICA}

ALTAMIRA Y CREVEA, R. (1951): "Plan y documentación de la Historia de las Municipalidades en las Indias españolas (siglos XVI-XVII)" en Contribuciones a la Historia Municipal de América. México D. F.

ARANGUIZ DONOSO, H. (1972): "Estudio institucional de los cabildos abiertos de Santiago de Chile (1541-1810), en III Congreso del Instituto Internacional de Historia del Derecho Indiano. Actas y Estudios. Instituto Nacional de Estudios Jurídicos, Madrid.

ARIAS DE GREIFF, A. (2003): "Las Cortes de Cádiz y la emancipación”, en Boletín de Historia y Antigüedades, vol. XC, No 823, Academia Colombiana de Historia.

BARAHONA, M. (1996): La Alcaldía Mayor de Tegucigalpa bajo el régimen de Intendencias (1788-1812). Honduras. Instituto Hondureño de Antropología e Historia. Tegucigalpa.

BAYLE, C. (1952): Los cabildos seculares en la América Española. Madrid.

BIDART CAMPOS, G.J. (1992): "El proceso político-constitucional de la república Argentina desde 1810 a la actualidad", en $A Y E R$.

BOIX, V. (1855): Apuntes históricos sobre los fueros del antiguo reino de Valencia. Valencia.

CHUST, M. (2000): “Revolución y autonomismo hispano: José Mejía Lequerica” en Revoluciones y revolucionarios en el mundo hispano. Castellón.

CHUST, M., FRASQUET, I, eds. (2004): La trascendencia del Liberalismo Doceañista en España y en América. Generalitat Valenciana, Biblioteca Valenciana. 
El papel de las ciudades en la construcción de la Nación

DOCUMENTOS RELATIVOS A LA JUNTA MONTEVIDEANA DE GOBIERNO

DE 1808. (1958): Montevideo. Junta Departamental de Montevideo.

DOMINGUEZ COMPANY, F. (1982): Ordenanzas Municipales Hispanoamericanas, Madrid-Caracas, 1982 "Funciones económicas del cabildo colonial hispanoamericano", (1951) en Contribuciones a la Historia Municipal de América, México, D. F.

EMILIANI, J.R. (1992): El cabildo, Cuadernos de Historia 13, Junta Provincial de Historia de Córdoba.

FERRERO MICÓ, R. (2001): "El cabildo como fuente de autonomía municipal”, en Revista del Archivo Histórico de la Municipalidad de Córdoba. № 2. Córdoba.

GANDÍA, E. de. (1960): Historia del 25 de Mayo. Nacimiento de la libertad y de la independencia argentinas, Buenos Aires.

GUERRA, F. X. (1992): Modernidad e Independencias. Ensayos sobre revoluciones hispánicas. Madrid. Fundación MAPFRE.

HAMNETT, Brian R. (1990): Raíces de la Insurgencia en México. Historia regional 1750-1824. México. Fondo de Cultura Económica.

HEREDIA, E.A. (1974): Planes españoles para reconquistar Hispanoamérica. 1810/ 1818. Argentina. Editorial Universitaria de Buenos Aires.

HOBSBAWN, E.J. (1990): Naciones y nacionalismo desde 1870. Barcelona.

MARTIRÉ, E. (2001): 1808. Ensayo histórico-jurídico sobre la clave de la emancipación hispanoamericana, Instituto de Investigaciones de Historia del Derecho, Buenos Aires.

MOUCHET, C. (1952): "Sarmiento y sus ideas sobre el municipio indiano", en $V$ Congreso Histórico Municipal Interamericano. Ciudad Trujillo, T.I.

OCAMPO LÓPEZ, Javier. (1982): "El Proceso Político Militar y Social de la Independencia", en Manual de Historia de Colombia. T.II.

OTS CAPDEQUÍ, J.M. (1940): “El régimen municipal hispano-americano del periodo colonial. Concejos y ciudades" en Estudios de Historia del Derecho Español en las Indias, Bogotá.

(1924) "Apuntes para la Historia del municipio Hispanoamericano del periodo colonial”, en Anuario de Historia del Derecho Español, Madrid. vol. I, pp 93-157.

Rhela. Vol. 12. Año 2009, pp. $111-128$ 
Independencia."

"El régimen municipal del Nuevo Reino de Granada al tiempo de la

El Estado Español en las Indias. Argentina. Buenos Aires. s.f.

PÉREZ O, E. (2005): La Guerra Irregular en la Independencia de la Nueva Granada y Venezuela. 1810-1830. Universidad Pedagógica y Tecnológica de Colombia.

PIVEL DEVOTO, J.E. (1957): Raíces coloniales de la Revolución de 1811, Montevideo.

PORRAS MUÑOZ, G. (1982): El gobierno de la ciudad de México en el siglo XVI. México. UNAM.

RODRÍGUEZ, M. (1984): El experimento de Cádiz en Centroamérica, 1808-1826). México. Fondo de Cultura Económica.

SÁENZ VALIENTE, J.M. (1952): Bajo la campana del cabildo. Organización y funcionamiento del cabildo de Buenos Aires después de la revolución de Mayo (1810-1821), Buenos Aires.

TORRES SANZ, X. (2008), Naciones sin nacionalismos, PUV.

ZORRAQUÍN BECÚ, R. (1960): “La doctrina jurídica de la revolución de mayo”, en Revista del Instituto de Historia del Derecho, $\mathrm{n}^{\circ}$ 11, 47, Buenos Aires.

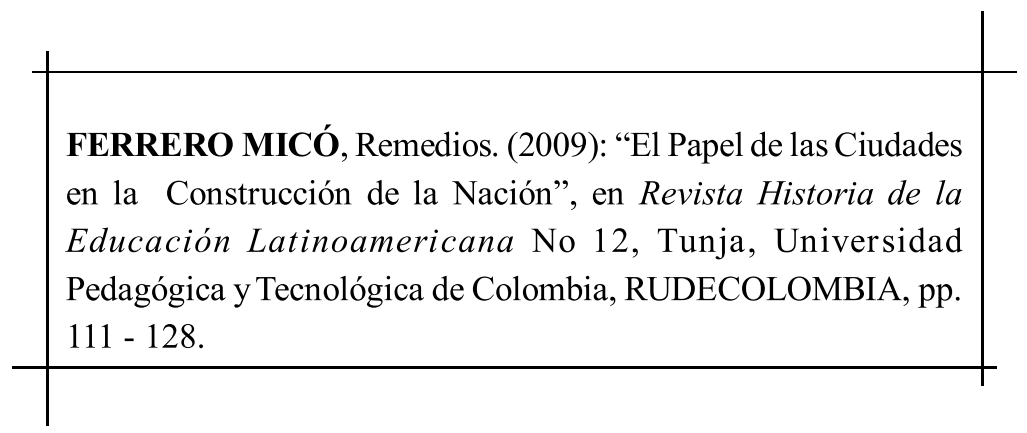

Rhela. Vol. 12. Año 2009, pp. $111-128$ 